Original Article

Journal of Epilepsy Research pISSN 2233-6249 / eISSN 2233-6257

Received October 6, 2020

Revised December 15, 2020

Accepted December 22, 2020

Corresponding author:

Priyanka Samuel, MPhil

School of Behavioural Science, National

Forensic Sciences University, Sector 9,

Gandhinagar 382007, India

Tel. $+91-8219389338$

Fax. +91-079-23247465

E-mail; priyanka.samuel@gfsu.edu.in

\section{Visual Motor and Executive Functioning in Adult Patients with Primary Generalized Epilepsy: A Pilot Study}

\author{
Priyanka Samuel, MPhil \\ School of Behavioural Science, National Forensic Sciences University, Gandhinagar, India
}

Background and Purpose: Epilepsy is a neuropsychological disorder which can lead to various cognitive deficits of varying levels. Primary generalized epilepsy is characterized by bilateral ictal electroencephalography patterns and excessive neural activity found in both hemispheres of the brain. There is dearth of research on primary generalized epilepsy in adult population. The present study investigates the visual motor and executive functioning deficits in patients with primary generalized epilepsy.

Methods: Study was conducted on 30 participants $(n=30)$ divided into target and normal control group. Target group consisted of patients diagnosed with primary generalized epilepsy with minimum 5 years of illness. Bender-Gestalt test (BGT) and Wisconsin's Card Sorting Test (WCST) was administered on both the groups.

Results: A significant difference was found between target group and control group's performances on BGT which indicates that visual motor functioning of control group was better than target group. A significant difference in executive functioning was found in performance of epilepsy patients and non-patients on the domains of WCST.

Conclusions: Both executive and visuomotor functioning are significantly affected in patients of primary generalized epilepsy in adult patients. (2020;10:62-68)

Key words: Epilepsy, Generalized epilepsy, Visual motor coordination, Executive functions, Cognitive dysfunctions

\section{Introduction}

Executive functions are the mental processes that enables an individual to perform tasks like paying attention, planning, organizing, reasoning, remembering, managing time and space, problem solving, and working memory. They include a group of interconnected functions that control purposeful, goal-directed, problem-solving behavior. Frontal lobe is associated with the executive functions we carry out. Different parts of frontal lobe are associated with corresponding cognitive functions. Dorsolateral prefrontal cortex is associated with verbal fluency, ability to maintain and shift set, response inhibition, organization, working memory, problem solving, reasoning and abstract thinking. ${ }^{1-4}$ Anterior cingulate cortex is associated with decision making, motivation behaviors, emotional drives and inappropriate response inhibition. ${ }^{5-7}$ Orbitofrontal cortex is concerned with maintaining set, controlling impulse, reinforcement on sensory stimuli and monitoring enduring and socially appropriate behaviors. ${ }^{8,9}$ Brain is directly affected in individuals having epilepsy which may be revealed as dysfunction or diminution in one or several cognitive functions. ${ }^{10,11}$ Cognition comprises of the capacity of brain to process information accurately and to program adaptive behavior. Primary generalized epilepsy is characterized by bilateral ictal electroencephalography (EEG) patterns and excessive neural activity found in both hemispheres of the brain. Seizures can affect the neurocognitive functioning of an individual. ${ }^{12-14}$ Hence, patients with epilepsy can have problems in their ability to learn and remember information, pay attention and focus, express themselves clearly, and etc. Recurrent seizures raise the chance of disturbance in brain functioning which can further lead to cognitive problems. Cognitive dysfunction and behavioral disorders are found more commonly in people with epilepsy. ${ }^{15}$

Impairment of sustained attention is most constantly designated in epilepsy. ${ }^{16}$ Kälviäinen et al. ${ }^{17}$ found that patients with epilepsy had difficulties in tasks that require memory, sustained attention even though they had normal attention span, normal psychomotor speed and normal speed of tracking. According to their study, memory difficulties can 
be due to attentional dysfunction, which leads to impaired or slowed initial encoding of memory trace, and deficit in storing process and hippocampal dysfunction. Gucuyener et al., ${ }^{18}$ Schubert, ${ }^{19}$ Kwan and Brodie, ${ }^{20}$ and Drane and Meador ${ }^{21}$ in their research established that antiepileptic drugs have a negative effect on attention and concentration of the individual. Pulsipher et al. ${ }^{22}$ in their research found impairment in executive functions in juvenile myoclonic subjects. Another study by Modi et al. ${ }^{23}$ conducted a study to recognize executive functioning phenotypes in youth with epilepsy and to observe if there is a difference of phenotypes on psychosocial and medical outcomes. They identified four executive functioning phenotypes which included four groups. Group 1 with no executive functioning deficits ( $45 \%$ of sample), group 2 included global executive functioning deficits ( $29 \%$ of sample), group 3 included behavioral regulation and working memory deficits ( $8 \%$ of sample), and group 4 included metacognitive deficits ( $17 \%$ of sample). The found no significant executive functioning phenotype group differences for seizure characteristics. Which indicated phenotypic variability in executive functioning is considerably related to patient-reported outcomes they also concluded that executive functioning phenotypic variability impacts quality of life differentially and psychosocial functioning. Neurocognitive interventions need to be individualized and tailored for the remediation of executive function deficits developed on phenotypes. Gelžinienè et al. ${ }^{24}$ conducted a study on 59 patients aged 14 to 17 years, meeting the diagnostic criteria for idiopathic generalized epilepsy and found the presence of executive dysfunction in patients with idiopathic generalized epilepsy. Similar findings were reported by Walsh et al. ${ }^{25}$ in patients with purely drug-refractory juvenile myoclonic epilepsy. Swartz et al. ${ }^{26}$ in his study found that patients with juvenile myoclonic epilepsy have impairment in visual working memory. Visual motor functioning is also affected in primary generalized epilepsy. ${ }^{27}$ Research by Perrine et al. ${ }^{28}$ indicates impact of epilepsy on psychomotor speed, verbal memory, which result in adversely affecting the quality of life of the individual. van Rijckevorsel ${ }^{13}$ and Kälviäinen et al. ${ }^{17}$ found that patients with epilepsy had difficulties in tasks requiring memory, sustained attention while they had normal attention span, simple psychomotor speed and simple speed of tracking. Research by Perrine et al. ${ }^{28}$ and Elger et al..$^{29}$ concluded that visuomotor functioning is affected in patients of epilepsy and it supports present results. In the study by Lee et al. ${ }^{30}$ it is stated that visuomotor speed and perception is affected by antiepileptic. Stores et al., ${ }^{31}$ Levav et al. ${ }^{32}$ Pavone et al. ${ }^{33}$ Aldenkamp et al., ${ }^{34}$ and Gallassi et al. ${ }^{35}$ found that psychomotor slowing is associated with epilepsy and antiepileptic drugs have an impact on visual motor and psychomotor

\section{functioning.}

The present study intends to investigate executive and visuomotor functioning in patients with primary generalized epilepsy. Impetus for taking up this investigation is availability of limited research on primary generalized epilepsy in adults, which elevates a need for further exploration of associated dysfunctions in primary generalized epilepsy. Most of the available researches are conducted on juvenile epilepsy. The findings of the research will be helpful in understanding the extent of impaired functionality in adults and a plan of cognitive remediation can be devised accordingly.

\section{Method}

Total number of participants in the study were 30. Out of which, 15 participants were from a target group and another 15 from a control group. The target group consisted of patients diagnosed with primary generalized epilepsy with minimum 5 years of illness. In the control group, individuals with no psychiatric or neurological illness were taken. Both the groups were matched in characteristics, i.e., age, sex, education, socioeconomic status. The research sample was selected using purposive sampling as per inclusion and exclusion criteria. Fifteen participants in the target group were selected from the Outpatient Department of Psychiatry from Civil Hospital, Gandhinagar. Fifteen normal individuals were selected in the control group from the community. Age, education and socio-demographic status were matched of both the groups. Inclusion criteria of the target group were: 1) patients clinically diagnosed with primary generalized epilepsy by a psychiatrist/neurologist; 2) patients between the age ranges of 20 to $45 ; 3$ ) patients of either sex and exclusion criteria included: 1) patients with history of substance abuse; 2) patients with diagnosed psychiatric illness; 3) patients with pre-existing psychiatric or organic conditions; 4) patients having epilepsy with mental retardation.

\section{Tools}

\section{Bender-Gestalt test (BGT)}

The BGT consists of nine designs, characterized by their gestalt, printed on a card. Each card is presented to the client and the client is instructed to copy each design on a paper. BGT is a test of perception and visuomotor functioning, which measures visual acuity and motor functioning. This test is most frequently used for brain dysfunction and can be used for child as well as adult population. 
Test retest reliability score was found to be reliability coefficient of 0.71 as per study by Pascal and Suttell. ${ }^{36}$ On retesting the subjects after a time interval between test and retest, they found the coefficient reliability of 0.63 .

\section{Wisconsin's card sorting test (WCST)}

WCST was initially developed to measure abstract reasoning ability and the ability to shift cognitive strategies in reaction to altering environmental contingencies. ${ }^{37}$ WCST is a measure of executive functioning of an individual. Executive function needs the ability to cultivate and conserve problem solving strategy across varying stimulus conditions in order to attain future goals. ${ }^{38,39}$ WCST consist of 128 response cards that depict figures of various forms like cross, star, circles and triangles of color red, green, blue, and yellow. There are four stimulus cards and those are placed from left to right order, i.e., one red triangle, two green stars, three yellow crosses, and four blue circles. A client is given the deck of 64 response cards and instructed to match each consecutive card from the deck with one of the four stimulus cards, whichever card he thinks matches. The client is given a feedback about every card he matches. He is only told whether each response is right or wrong. There are three sorting categories which is not told to the client. These categories are: color, form, and number. Once the client makes 10 consecutive correct responses, the category is changed and the client has to shift his mental set and change the category. Patients having frontal lobe dysfunction have significant difficulty in shifting mental-set, management, planning, organization and etc. It can be used for clients in the age range of 6 and half years to 89 years of age.

\section{Procedure}

Clearance from the ethical committee was taken for this research and informed consent was obtained by all the participants before the commencement of the research. Participants were selected from Civil Hospital, Gandhinagar and Hospital for Mental Health, Gandhinagar.
Participants of the control group were clinically diagnosed by psychiatrists. EEG reports were also obtained to verify the diagnosis. IQ reports were verified to rule out mental retardation with epilepsy. Participants of both the target group and control group were thoroughly explained about the nature and purpose of the study and they were explained about the rationale of neuropsychological testing. They were then assessed on neuropsychological tests, i.e., BGT and WCST. Appropriate instructions were given to the subjects and as-

Table 2. Characteristics of the participants of target and control group

\begin{tabular}{lc}
\hline Characteristic & Frequency \\
\hline Sex & \\
Target group & \\
$\quad$ Male & $7(46.7)$ \\
$\quad$ Female & $8(53.3)$ \\
Control group & \\
$\quad$ Male & $7(46.7)$ \\
$\quad$ Female & $8(53.3)$ \\
SES $\quad$ \\
Target group & \\
Low & \\
$\quad$ Middle & $11(73.3)$ \\
Low-middle & $2(13.3)$ \\
High & $2(13.3)$ \\
Control group & - \\
Low & \\
Middle & $7(46.7)$ \\
Low-middle & $4(26.7)$ \\
High & $4(26.7)$ \\
IIIness duration & - \\
Target group & \\
$>5$ to 10 years & \\
\hline Control group & \\
\hline
\end{tabular}

Values are presented as number (\%).

SES, socioeconomic status.

Table 1. Characteristics of the participants of target and control group

\begin{tabular}{lcccc}
\hline Characteristic & Minimum & Maximum & Mean & Standard deviation \\
\hline Target group & & & & \\
Age & 20.00 & 49.00 & 8.93 & 8.47 \\
$\quad$ Education & 5 & 12 & & 2.64 \\
Control group & & & 33.33 & 10.01 \\
Age & 20.00 & 45.00 & 10.07 & 3.17 \\
Education & 5.00 & 15.00 & & \\
\hline
\end{tabular}


sessment was carried out in one to two sessions. Test atmosphere was calm and peaceful and distractions were avoided as far as possible. After administration, tests were scored as per the scoring procedure given in the test manual of respective tests.

\section{Results}

Mann-Whitney test was used for statistical analysis of data. Mann-Whitney test is a non-parametric test used on small sample when two groups are not in normal probability range. It compares two conditions and determines whether two samples are different in an independent group design. Kolmogorov Smirnov Z test was applied for determining the normal probability of data. Since data was skewed, Mann-Whitney test was applied. SPSS (ver. 17.0; SPSS Inc., (hicago, IL, USA) was used for the statistical analysis. The characteristics of the participants in the target and control group are given in Tables 1 and 2. In the target group there were eight females and seven males. Mean age was 30.93 years and standard deviation (SD) was 8.47. Mean education was 8.46 and SD was 2.64. Eleven participants were from low socioeconomic status, two from low middle and another two from low middle socioeconomic status. Eight participants had illness duration of 5 to 10 years and seven had more than 10 years. In the control group there were eight females and seven males. Mean age was 33.33 years and SD was 10.01. Mean education was 10.07 and SD was 3.173. Seven participants were from low socioeconomic status and four from middle and four from low middle

Table 3. Mann-Whitney $U$ test values for Bender-Gestalt test

\begin{tabular}{lc}
\hline & Dysfunction rating \\
\hline Mann-Whitney $U$ & $55.50 *$ \\
$Z$ & -2.54 \\
$p$-value & 0.016 \\
\hline *Level of significance at 0.01 level.
\end{tabular}

socioeconomic status. On BGT, significant values were found on dysfunction rating (target group mean rank, 11.70; control group mean rank, 19.30; Mann-Whitney $U=55.50 ; Z=-2.54 ; p \leq 0.05$ level; Table $3)$, indicating that there was a significant difference in visuomotor functioning of normal individuals and epileptic patients. On Wisconsin's card sorting test, as shown in Table 4, there was a significant difference between the total number of errors of the target group and control group (target group mean rank, 8.00; control group mean rank, 23.00; Mann-Whitney $U=0.00 ; Z=-4.67 ; p \leq$ 0.001 level) and in percent errors (target group mean rank, 8.80; control group mean rank, 22.20; Mann-Whitney $U=12.00 ; Z=-4.18$; $p \leq 0.001$ level). There was also a significant difference between the target group and control group in: perseverative responses (target group mean rank, 9.73; control group mean rank, 21.27; Mann-Whitney $U=26.00 ; Z=-3.62 ; p \leq 0.001)$; percent perseverative responses (target group mean rank, 9.93; control group mean rank, 21.07; Mann-Whitney $U=29.00 ; Z=-3.49 ; p \leq 0.001$ level); and perseverative errors (target group mean rank, 8.60; control group mean rank, 22.40; Mann-Whitney $U=9.00 ; Z=-4.35 ; p \leq$ 0.001 level). There was a significant difference in set task shifting ability of the target group and control group in percent perseverative errors (Mann-Whitney $U=52.00, Z=-2.00, p \leq 0.01$ ), attention between the target group and control group in non-perseverative errors (target group mean rank, 11.50; control group mean rank, 19.50; Mann-Whitney $U=26.00 ; Z=-3.62 ; p \leq 0.01)$, capacity of abstraction in the target group and control group in percent conceptual level response (target group mean rank, 2.00; control group mean rank, 9.00; Mann-Whitney $U=15.00 ; Z=-4.57 ; p \leq 0.001$ level), set shifting and ability to complete categories between the target group and control group in number of categories completed (target group mean rank, 10.00; control group mean rank, 21.00; Mann-Whitney $U=30.00 ; Z=-3.98 ; p \leq 0.001$ level), conceptualization abilities between the target group and control group in trials to complete first

Table 4. Mann Whitney $U$ test values for Wisconsin's card sorting test

\begin{tabular}{|c|c|c|c|c|c|c|c|c|c|c|c|c|c|}
\hline & $\begin{array}{l}\text { Total No. } \\
\text { of errors }\end{array}$ & $\%$ errors & $\begin{array}{c}\text { Persevera } \\
\text { tive } \\
\text { responses }\end{array}$ & $\begin{array}{l}\text { \% persev- } \\
\text { erative } \\
\text { responses }\end{array}$ & $\begin{array}{l}\text { Persevera } \\
\text { tive errors }\end{array}$ & $\begin{array}{c}\text { \% persev- } \\
\text { erative } \\
\text { errors }\end{array}$ & $\begin{array}{c}\text { Non per- } \\
\text { severative } \\
\text { errors }\end{array}$ & $\begin{array}{c}\% \\
\text { non-per- } \\
\text { severative } \\
\text { errors }\end{array}$ & $\begin{array}{l}\% \text { con- } \\
\text { ceptual } \\
\text { level }\end{array}$ & $\begin{array}{l}\text { No. of cate- } \\
\text { gories } \\
\text { completed }\end{array}$ & $\begin{array}{c}\text { Trials to } \\
\text { complete } \\
\text { 1st } \\
\text { category }\end{array}$ & $\begin{array}{c}\text { Failure to } \\
\text { maintain } \\
\text { set }\end{array}$ & $\begin{array}{l}\text { Learning } \\
\text { to learn }\end{array}$ \\
\hline$U$ & $0.00 *$ & $12.00 *$ & $26.00^{*}$ & $29.00^{*}$ & $9.00 *$ & $34.00^{*}$ & $52.50^{*}$ & 69.00 & $15.00^{*}$ & $30.00^{*}$ & $58.50^{\dagger}$ & 100.5 & $40.50^{*}$ \\
\hline Z & -4.677 & -4.18 & -3.624 & -3.499 & -4.354 & -3.302 & -2.491 & -1.806 & -4.574 & -3.985 & -2.369 & -0.713 & -3.501 \\
\hline$p$-value & 0 & 0 & 0 & 0 & 0 & 0.001 & 0.011 & 0.074 & 0 & 0 & 0.023 & 0.624 & 0.002 \\
\hline
\end{tabular}

*Level of significance at 0.001 level.

'Level of significance at 0.05 level. 
category (target group mean rank, 14.70; control group mean rank, 16.30; Mann-Whitney $U=58.50 ; Z=-2.36 ; p \leq 0.05$ level), and efficiency to change categories between the target group and control group in learning to learn (target group mean rank, 10.70; control group mean rank, 20.30; Mann-Whitney $U=40.50 ; Z=-3.50 ; p \leq$ 0.001 level).

\section{Discussion}

Epilepsy is associated with several cognitive dysfunctions which can add to the distress of the patients. It is hence helpful to understand the associated cognitive dysfunctions in order to plan and provide focused intervention. As per the results of the study, following outcomes were observed.

\section{Visuomotor functioning}

A significant difference was found between the target group and control group's performances on the BGT, which indicates that visuomotor functioning of the control group was better than the target group. Research by Perrine et al., ${ }^{28}$ Elger et al., ${ }^{29}$ Lee et al., ${ }^{30}$ Stores et al. ${ }^{31}$ Levav et al., ${ }^{32}$ Pavone et al., ${ }^{33}$ Aldenkamp et al. ${ }^{34}$ and Gallassi et al. ${ }^{35}$ also found impact of epilepsy on visuomotor and psychomotor functioning, which supports our study results. Although studies, e.g., Lee et al., ${ }^{30}$ Levav et al., ${ }^{32}$ and Pavone et al. ${ }^{33}$ found the association of antiepileptic drugs and visual motor functioning and it needs to be kept in consideration as antiepileptic drugs may be associated with the visuomotor deficits.

\section{Executive functioning}

Results reveal that the control group performed better than the target group. A significant difference was found between performance of epilepsy patients and that of non-patients on the domains of WCST.

Total number of errors, percent errors, perseverative responses, percent perseverative responses, perseverative errors, percent perseverative errors, non-perseverative errors, percent conceptual level responses, number of categories completed, trials to maintain first category and learning to learn scores were found highly significant indicating substantial difference in performance of both groups on WCST, which indicates dysfunction of task shifting ability, attention, abstraction ability, conceptualization, and ability to change and complete categories. The normal control group performed better than the target group. Examining the mean ranks of conceptual level re- sponses, it is observed that performance of the target group is higher than the normal control group and the reason is that conceptual level responses indicate the inability to maintain and complete category. Hence it can be stated that executive functioning of epileptic patients is affected.

Hamed, ${ }^{40}$ Devinsky et al., ${ }^{41}$ and Piazzini et al., ${ }^{42}$ in their research found that problems in executive functions are associated with epilepsy, which supports our results. Horner et al. ${ }^{43}$ in their research found high scores on perseveration indices in patients of epilepsy, which indicates inability to shift set, and is suggestive of dysfunction of prefrontal lobe, which is also in accordance to our research.

\section{Conclusion, limitations and future directions}

The study was conducted on a small sample as a pilot study. A larger sample will lead to better generalization and understanding of the dysfunctions. Another limitation of the study was that all the characteristics of the sample could not be matched since the data was collected in a limited period of time in a clinical setup. The major difference in the baseline characters was of socio economic status, while education is matched. Socio economic status alone can't affect cognition. Difference in socio economic status with similar years of education can attribute to differences in attitude and cultural practices or life style and other aspects of behavior with no impact on cognition or neuropsychological functioning. Determining the dysfunction associated with the type of primary generalized epilepsy can provide better outcome in terms of understanding the impairment due to epilepsy which could not be done in the present study due to small sample size. The tests used were mainly descriptive of functional ability or neuropsychological dysfunction. Additionally, assessments like the Benton judgement of line orientation test can be administered, determining visuo-perceptual functioning and dysfunction along with the BGT that assesses the visuomotor dysfunction.

Tests that assess on localization of the brain like Luria Nebraska Neuropsychological battery or other neuropsychological batteries simultaneously administered with EEG recording can be more thorough and helpful in understanding of neuropsychological functioning in patients of epilepsy.

Severity of epilepsy can be taken into consideration and compared with related neuropsychological functioning. Lastly, the difference in education was determined in the target group and control group and the IQ differences were not observed, which could provide more appropriate and confirmatory results.

As per the findings of the current study, it can hence be concluded 
that both executive and visuomotor functioning are affected in patients of primary generalized epilepsy. However, further research is needed to generalize results. Neuropsychological assessments precisely assess the localization, lateralization and functioning of the brain, and the areas affected due to any brain insult or the involvement of the brain area in epilepsy. Assessment of patients with epilepsy on specific domains using neuropsychological tests can be further helpful in establishing a holistic management plan or providing the required support in case of any existing deficits and also help a person's function up to the maximum capacity. ${ }^{44}$

\section{References}

1. Gioia GA, Isquith PK, Guy SC, Simeonsson RJ. Assessment of executive functions in children with neurological impairment. In: Rosenthal SL, Simeonsson RJ, eds. Psychological and developmental assessment: children with disabilities and chronic conditions. 1st ed. New York: The Guilford Press, 2001;317-56.

2. Shimamura AP. The role of the prefrontal cortex in dynamic filtering. Psychobiology 2000;28:207-18.

3. Naismith SL, Shine JM, Lewis SJ. The specific contributions of set-shifting to freezing of gait in Parkinson's disease. Mov Disord 2010;25:1000-4.

4. Kane MJ, Engle RW. The role of prefrontal cortex in working-memory capacity, executive attention, and general fluid intelligence: an individual-differences perspective. Psychon Bull Rev 2002;9:637-71.

5. Miller BL, Cummings JL. The human frontal lobes: functions and disorders. 2nd ed. New York: The Guilford Press, 2007;355-6.

6. Aron AR. From reactive to proactive and selective control: developing a richer model for stopping inappropriate responses. Biol Psychiatry 2011;69:e55-68.

7. Crews FT, Boettiger CA. Impulsivity, frontal lobes and risk for addiction. Pharmacol Biochem Behav 2009;93:237-47.

8. Rolls ET. The functions of the orbitofrontal cortex. Brain Cogn 2004;55: $11-29$.

9. Rolls ET. Convergence of sensory systems in the orbitofrontal cortex in primates and brain design for emotion. Anat Rec A Discov Mol Cell Evol Biol 2004;281:1212-25.

10. Bergen DC. Do Seizures harm the brain? Epilepsy Curr 2006;6:117-8.

11. Thompson PJ, Duncan JS. Cognitive decline in severe intractable epilepsy. Epilepsia 2005;46:1780-7.

12. Vingerhoets G. Cognitive effects of seizures. Seizure 2006;15:221-6.

13. van Rijckevorsel K. Cognitive problems related to epilepsy syndromes, especially malignant epilepsies. Seizure 2006;15:227-34.

14. Motamedi G, Meador K. Epilepsy and cognition. Epilepsy Behav 2003;4 Suppl 2:S25-38.

15. Cornaggia $C M$, Beghi M, Provenzi M, Beghi E. Correlation between cognition and behavior in epilepsy. Epilepsia 2006;47 Suppl 2:34-9.
16. Sánchez-Carpintero R, Neville BG. Attentional ability in children with epilepsy. Epilepsia 2003;44:1340-9.

17. Kälviäinen R, Aikiä M, Helkala EL, Mervaala E, Riekkinen PJ. Memory and attention in newly diagnosed epileptic seizure disorder. Seizure 1992;1:255-62.

18. Gucuyener K, Erdemoglu AK, Senol S, Serdaroglu A, Soysal S, Kockar Al. Use of methylphenidate for attention-deficit hyperactivity disorder in patients with epilepsy or electroencephalographic abnormalities. J Child Neurol 2003;18:109-12.

19. Schubert R. Attention deficit disorder and epilepsy. Pediatr Neurol 2005;32:1-10.

20. Kwan P, Brodie MJ. Neuropsychological effects of epilepsy and antiepileptic drugs. Lancet 2001;357:216-22.

21. Drane DL, Meador KJ. Cognitive and behavioral effects of antiepileptic drugs. Epilepsy Behav 2002;3(5S):49-53.

22. Pulsipher DT, Seidenberg M, Guidotti L, et al. Thalamofrontal circuitry and executive dysfunction in recent-onset juvenile myoclonic epilepsy. Epilepsia 2009;50:1210-9.

23. Modi AC, Gutierrez-Colina AM, Wagner JL, et al. Executive functioning phenotypes in youth with epilepsy. Epilepsy Behav 2019;90:112-8.

24. Gelžiniene $G$, Jurkevičiene $G$, Marmiene $V$, Adomaitiene $V$, Endziniene M. Executive functions in adolescents with idiopathic generalized epilepsy. Medicina (Kaunas) 2011;47:313-9.

25. Walsh J, Thomas RH, Church C, Rees MI, Marson AG, Baker GA. Executive functions and psychiatric symptoms in drug-refractory juvenile myoclonic epilepsy. Epilepsy Behav 2014;35:72-7.

26. Swartz BE, Simpkins $F$, Halgren $E$, et al. Visual working memory in primary generalized epilepsy: an 18FDG-PET study. Neurology 1996;47:1203-12.

27. Pulliainen $V$, Kuikka $P$, Jokelainen $M$. Motor and cognitive functions in newly diagnosed adult seizure patients before antiepileptic medication. Acta Neurol Scand 2000;101:73-8.

28. Perrine K, Hermann BP, Meador KJ, et al. The relationship of neuropsychological functioning to quality of life in epilepsy. Arch Neuro/ 1995; 52:997-1003.

29. Elger $C E$, Helmstaedter C, Kurthen M. Chronic epilepsy and cognition. Lancet Neurol 2004;3:663-72.

30. Lee $S$, Sziklas $V$, Andermann $F$, et al. The effects of adjunctive topiramate on cognitive function in patients with epilepsy. Epilepsia 2003;44:339-47.

31. Stores G, Williams PL, Styles E, Zaiwalla Z. Psychological effects of sodium valproate and carbamazepine in epilepsy. Arch Dis Child 1992;67:1330-7.

32. Levav M, Mirsky AF, Herault J, Xiong L, Amir N, Andermann E. Familial association of neuropsychological traits in patients with generalized and partial seizure disorders. J Clin Exp Neuropsychol 2002;24:311-26.

33. Pavone $P$, Bianchini $R$, Trifiletti RR, Incorpora G, Pavone A, Parano E. Neuropsychological assessment in children with absence epilepsy. Neurology 2001;56:1047-51.

34. Aldenkamp AP, Alpherts WC, Blennow G, et al. Withdrawal of antiepileptic medication in children--effects on cognitive function: the multicenter Holmfrid study. Neurology 1993;43:41-50. 
35. Gallassi R, Morreale A, Di Sarro R, Marra M, Lugaresi E, Baruzzi A. Cognitive effects of antiepileptic drug discontinuation. Epilepsia 1992;33 Suppl 6:S41-4.

36. Pascal GR, Suttell BJ. The Bender-gestalt test. New York: Grune \& Stratton, 1951.

37. Grant DA, Berg EA. A behavioral analysis of degree of reinforcement and ease of shifting to new responses in a Weigl-type card-sorting problem. J Exp Psychol 1948;38:404-11.

38. Luria AR. The working brain: introduction to neuropsychology. Harmondsworth: Penguin Books, 1973.

39. Shallice T. Specific impairments of planning. Philos Trans $R$ Soc Lond B Biol Sci 1982;298:199-209.

40. Hamed SA. The aspects and mechanisms of cognitive alterations in epilepsy: the role of antiepileptic medications. CNS Neurosci Ther 2009;15:
134-56.

41. Devinsky O, Gershengorn J, Brown E, Perrine K, Vazquez B, Luciano D. Frontal functions in juvenile myoclonic epilepsy. Neuropsychiatry Neuropsychol Behav Neurol 1997;10:243-6.

42. Piazzini A, Turner K, Vignoli A, Canger R, Canevini MP. Frontal cognitive dysfunction in juvenile myoclonic epilepsy. Epilepsia 2008;49:657-62.

43. Horner MD, Flashman LA, Freides D, Epstein CM, Bakay RA. Temporal lobe epilepsy and performance on the Wisconsin card sorting test. J Clin Exp Neuropsychol 1996;18:310-3.

44. Akdag S. Epilepsy and neurology [Internet]. Vancouver: BC Epilepsy Society Newsletter, 2009 [cited 2009 Spring]. Available at: http://bcepilepsy.com/files/information-sheets/Epilepsy_and_ Neuropsychology.pdf. 